\title{
How to Sustain and Spread Nutritional Care Improvements
}

\author{
Celia V. Laur and Jack J. Bell
}

\section{Abstract}

Previous chapters have described how to improve nutrition care with an emphasis on interdisciplinary approaches. The focus of this chapter is on keeping these improvements going (sustainability) and how to apply them to a new setting (spread).

\section{Keywords}

Sustainability · Spread - Quality of healthcare - Implementation · Nutrition · Evaluation · Equity

This chapter is a component of Part 1: Nutritional Care in Old Age.

For an explanation of the grouping of chapters in this book, please see Chap. 1: "Overview of Nutrition Care in Geriatrics and Orthogeriatrics."

\section{V. Laur $(\bowtie)$}

Women's College Hospital Institute for Health System Solutions and Virtual Care, and Women's College Research Institute, Women's College Hospital, Toronto, ON, Canada e-mail: Celia.Laur@wchospital.ca

\section{J. J. Bell}

Allied Health, The Prince Charles Hospital, Chermside, Queensland, Australia

School of Human Movement and Nutrition Sciences, The University of Queensland, St Lucia, QLD, Australia

e-mail: jack.bell@health.qld.gov.au

Ó. G. Geirsdóttir, J. J. Bell (eds.), Interdisciplinary Nutritional Management and 


\section{Learning Outcomes}

By the end of this chapter, you will be able to:

- Understand the key elements of sustainability and differentiate between spread and scale.

- Formulate strategies to include sustainability from the beginning of nutrition care improvements.

- Justify elements integral to building, sustaining, and spreading nutrition care improvements.

- Recognize common barriers and enablers to sustaining and spreading nutrition care improvements.

- Know some tools to use to help support sustainability planning.

- Recognize the importance of equity considerations in planning for sustainability and spread.

\subsection{Getting Started}

When you make a change that improves practice, you want to make sure that it continues to have the desired benefit. This is why it is important to think about sustainability of interventions or programs from the beginning of your work. There are ways to integrate sustainability plans from the beginning and strategies to use once the initiative is working to help make sure that the processes and benefits continue. Another way to have a longer-term impact is to have your work used in other locations by spreading the program or improvement. This chapter will go through definitions, strategies, barriers, and enablers to sustainability and spread, drawing on case examples from Canada and Australia.

\subsubsection{Definitions}

A major challenge when talking about sustainability is that there is no consistent definition or length of time used to determine if a program was "sustained" [1-5]. There are also many terms used to describe this concept, such as maintenance, normalization, institutionalization, and routinization [3, 6]. Moore et al.'s (2017) definition of sustainability is commonly used as it breaks sustainability into five main components regarding time, continued delivery of the intervention and/or behavior change, and recognition that the program may continue to adapt in order to produce benefits for individual/systems [3] (p. 6). As put by Scheirer and Dearing, sustainability is the "continued use of program components and activities for the continued achievement of desirable program and population outcomes" [7].

When planning for the use of a program or improvement in another setting, two common ways to explain this process are spread and scale. As with sustainability, there are no consistent definitions for spread and scale. This chapter focuses on spread, but it is important to understand the difference since these concepts are often 
used interchangeably. Differentiating between these concepts allows for more targeted strategies. Greenhalgh et al. (2019) define spread as "Replicating an initiative somewhere else (i.e. one site to another)" and scale as "Tackling the infrastructure problems that arise during full scale implementation (i.e. implementing provincial policy)" [8, 9]. Shaw et al. [10] further indicate that spread is for "complex" problems where following a specific formula may not work and you may need to extensively adapt the program to fix the context. Scale is for "complicated" problems where formulas are critical and a high level of expertise is needed, yet solutions do not need to be adapted $[10,11]$. As an example, if a nutrition care program that was working well in one long-term facility was taken up in another and adapted to that setting, it would be called spread, while if a specific change were made across all facilities, this would be scale.

\subsection{Case Example: Improving Nutrition Care in Hospital}

To further understand the concepts of sustainability and spread, this case example, led by Prof Heather Keller from the University of Waterloo, demonstrates how hospitals across Canada were able to implement nutrition care activities including nutrition screening and assessment $[12,13]$, sustain those changes for several years [14], and spread to new hospitals with minimal researcher involvement [14]. This grassroot, or "bottom-up," approach focused on implementation, sustainability, and spread, while complemented by "top-down" effort from the Canadian Malnutrition Task Force, the Canadian Nutrition Society, and the Health Standards Organization to develop malnutrition standards which could be scaled across Canada.

\subsubsection{Initial Implementation and Considering Sustainability from the Beginning}

Five hospitals across Canada were tasked with implementing the Integrated Nutrition Pathway for Acute Care (INPAC), a consensus-based pathway for the prevention, detection, and treatment of hospital malnutrition $[15,16]$. After 1 year, a multidisciplinary team of hospital staff and management had implemented nutrition screening and a standardized assessment [12], decreased barriers to food intake (i.e., when the meal tray is too far from the patient), and increased food intake monitoring [12, 17]. Another year later, those changes continued [14], and six new hospitals that had started INPAC implementation were able to reach similar levels with less support from a research team [14].

A summary of strategies for initial implementation of INPAC is provided in Fig. 11.1, and strategies for sustainability and spread are in Fig. 11.2. These figures are based on interviews and focus groups with those involved in the original five hospitals $[13,18]$. An INPAC implementation toolkit has also been developed which walks through steps for implementation and sustainability (http://m2e.nutritioncareincanada.ca/).

To implement INPAC, a multidisciplinary implementation team worked together to build a reason to change practice. These reasons varied slightly depending on the 


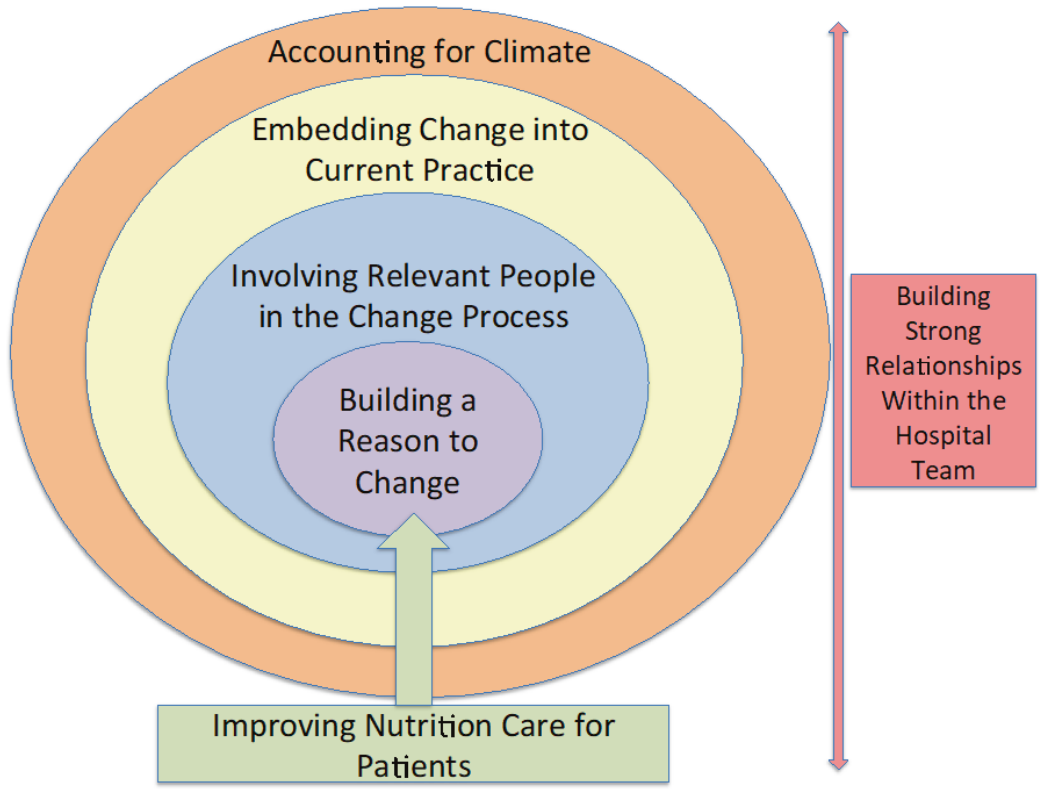

Fig. 11.1 A visual summary of how hospitals implemented nutrition care improvements and built the foundation for sustainable change [18]. (The figure is used with permission)

audience (management, nurses, and others), typically demonstrating the national and local prevalence (i.e., one in three patients are malnourished at admission) [1922], the impact on length of stay (i.e., malnourished patients stay 2-3 days longer) [23], and the cost (i.e., approximately $\$ 2$ billion CAN per year) [24]. These reasons for change were coupled with potential solutions, including ways that everyone can be involved in improving nutrition care.

This multidisciplinary approach led to the next main factor for change which was about involving the right people in the change process, including those most impacted (i.e., admission nurses who conduct nutrition screening). To be sustained, all changes had to be embedded into current practice, such as by adapting existing workflows and working with those impacted to see what made the most sense in that unit/hospital.

Context was key, so considering the external factors, such as hospital structure and overall climate, was needed. Climate focuses on the values of the organization, including the means, motivation, and opportunities for innovation [25]. For example, changes need to be within the regulations of the health region (context), while aligning with the hospital priorities (climate). Finally, strong relationships within the hospital teams were required throughout the change process, a factor that continues to apply through sustainability and spread. 


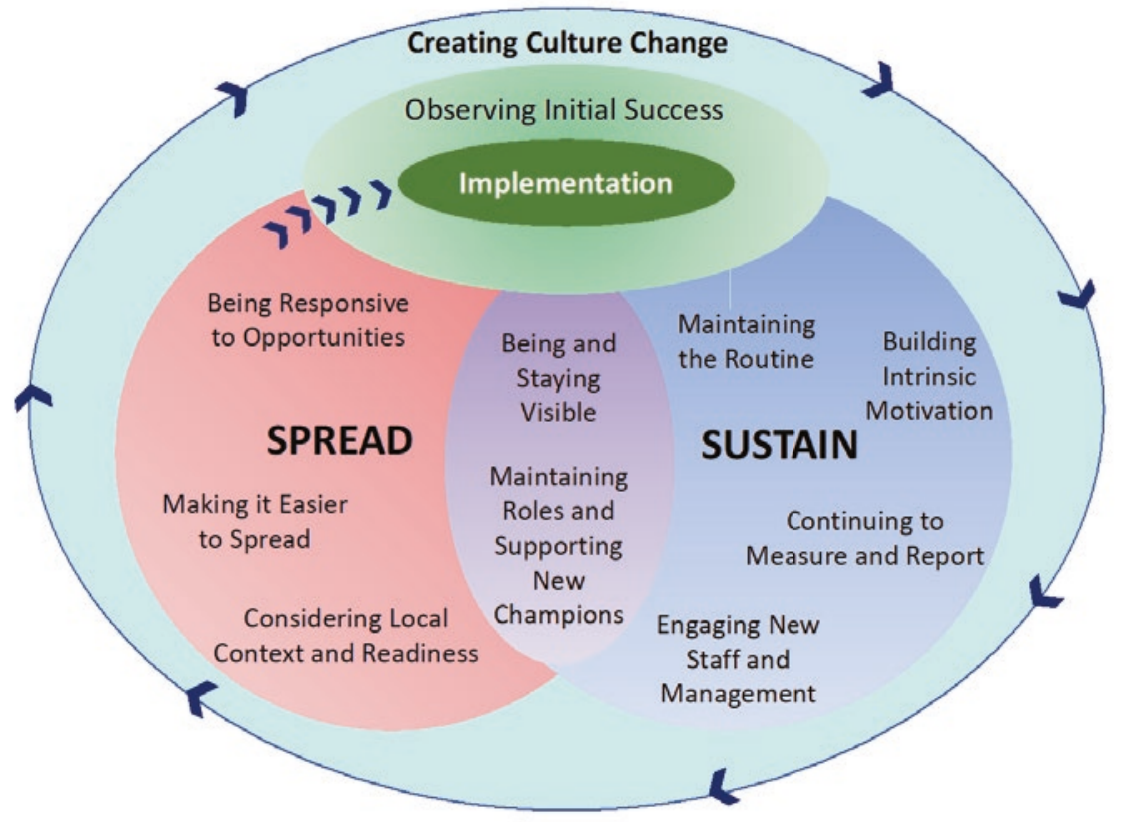

Fig. 11.2 The sustain and spread framework. This summary of strategies to support sustainability and spread begins once there is some initial implementation success.

\subsubsection{Strategies for Sustainability and Spread}

Nutrition care improvements, specifically nutrition screening and assessment, were sustained and spread [14]. Strategies for how these changes were sustained were explored with the original hospitals 1 year after initial implementation [13] and again 2 years later with six new hospitals [26]. A summary of these strategies is provided in Fig. 11.2.

Figure 11.1 could be placed in the "implementation" oval of Fig. 11.2. Strategies to encourage changes to be sustained or spread are included within each large circle, with the two overlapping strategies in the middle relevant to sustaining and spreading success. To spread to a new setting, it goes back to initial implementation (arrows from the spread circle back to implementation) in the new context. Working through several rounds of sustaining and spreading may potentially lead to culture change. The figure is used with permission [13].

To achieve sustainability, the multidisciplinary teams focused on maintaining the routine, building intrinsic motivation, continuing to measure and report, as well as engaging new staff and management. High staff turnover was common, making orientation sessions and quick introduction chats with new management key for continued success. Regular audits were also important, allowing teams to see their progress and to know when "booster" activities, such as reminders, were needed to 
maintain the momentum. Audits were less frequent than during initial implementation.

For spread, the teams mentioned the importance of being responsive to opportunities such as interest from other locations and finding ways to make it easier by learning from previous implementation experience. As with initial implementation, the new context needed to be considered, as well as how ready the new location was to start implementation. In the new location, the change needed to start again, thinking through each factor of implementation, ideally learning from what has come before.

Strategies important for both sustaining and spreading changes were about being and staying visible, such as having a member of the team regularly present where the change was taking place. Champions, those that bring the implementation efforts forward, were key to success. Champions for specific tasks or new locations were needed in order to decrease the burden on the original champion and facilitate sustainability. Attributes for effective champions have been suggested, such as influence, ownership, physical presence at the point of change, persuasiveness, grit, and a participative leadership style [27].

This case example was conducted in Canada, and the frameworks have not been validated in other settings. However, the Systematized, Interdisciplinary Malnutrition Pathway for impLementation and Evaluation (SIMPLE) in hospitals is based on INPAC and has used these strategies for improving nutrition care in Australia $[28,29]$.

\subsection{Tools for Sustainability and Spread}

There are many theories, models, frameworks, and tools that can be used as guides for implementation, sustainability, and spread [30, 31]. Although some tools may be more directed toward initial implementation and others toward sustainability, the most important factor is choosing what works for you and your team, and ideally, validated. A more detailed tool may provide useful ideas about factors to consider yet may not be practical for everyday use. Others may be too simplistic, focusing on key questions without providing direction on what to do with the information. Training courses have been developed, such as those from the Center for Implementation (https://thecenterforimplementation.com/courses), which can introduce you to several options and help you decide what makes sense for your work.

\subsubsection{Sustainability Tools}

While implementation tools can be used to plan for implementation and sustainability, it is recommended that sustainability be considered from the beginning, rather than only at the end, where it is typically placed. There are also tools focused on sustainability: 
- Program Sustainability Assessment Tool (PSAT): This is designed to support the implementation of an evidence-based program, typically in the community. The tool has several resources that help you understand, assess, review, and plan for sustainability [32]. The Clinical Sustainability Assessment Tool is also available (https://www.sustaintool.org/).

- The NHS Sustainability Model and Guide: This model focuses on staff, process, and organization and is designed to be used at several points throughout your implementation. This model allows you to work through a checklist and provides a quantitative score to inform your next steps [33].

\subsection{Monitoring and Evaluation}

It is difficult to know if the intended benefit or process is continuing without measuring it. Monitoring and evaluation are essential factors for initial implementation, and continued monitoring will allow you to know if your processes and outcomes are sustained [34]. The frequency of this monitoring may not need to be the same as during the earlier stages of implementation; however, an occasional check on progress will let you know if further effort or "boosters" are needed.

\subsection{Barriers and Facilitators}

There are many barriers and facilitators to implementation, sustainability, and spread [35-38]. Examples of facilitators include the continued role of the champion, ongoing organizational leadership and support, adequate funding and resources, continued effectiveness of the program, setting characteristics and policies, and fit of the program/intervention within the context. Examples of barriers include lack of funding, high staff turnover, or changes in policy. Using preestablished lists of barriers and facilitators [35-37] can help you think through possible factors; however, it is important to understand which factors are impacting your specific work before trying to overcome barriers that may not exist in your setting. Monitoring and evaluation, including discussions with those involved, can facilitate this understanding.

\subsection{Considering Equity}

When planning for a nutrition improvement to be sustained, spread, or scaled, it is important to take an equity lens to ensure the improvement is equitable, and not perpetuating or exacerbating existing inequities. Improvements also need to acknowledge the diverse experiences that impact implementation efforts and account for social influence, such as sociopolitical forces, physical structures, and economics [39]. A key goal in this work is to improve the quality and outcomes of services and make treatments and services available to multiple communities and 
settings [40, 41]. To achieve this goal, Baumann and Cabassa (2020) have listed five strategies [41]:

1. Focus on reach from the very beginning.

2. Design and select interventions for vulnerable populations and low-resource communities with implementation in mind.

3. Implement what works and develop implementation strategies that can help reduce inequities in care.

4. Develop the science of adaptations.

5. Use an equity lens for implementation outcomes.

\subsection{Summary}

When making nutrition care improvements in any setting, changes should be planned with the potential for sustainability and spread considered from the beginning. Focusing on improvements that are unlikely to be sustained can lead to wasted time and resources, which can be discouraging when trying to involve and motivate others for the next change. Not everything needs to be sustained and spread; evaluation and equity are key to this decision. Healthcare is constantly changing, making adaptability and flexibility key, and considering how to sustain or spread your improvement from the beginning will be beneficial for success.

\section{Take-Home Points}

- Sustainability and spread should be considered and planned for, if relevant, from the beginning of any change process.

- Sustainability is difficult to define; definitions typically focus on the continuation of program components which lead to the continuation of the desired outcomes.

- Distinguishing between spread and scale allows for more strategic approaches to have your nutrition care improvement used in other settings.

- Regular monitoring and evaluation allow for understanding of how a change is progressing and if "boosters" or reminders are needed.

- An equity lens is needed so that by sustaining and spreading nutrition care improvements you are not also sustaining and spreading inequities.

\section{References}

1. Ilott I et al (2013) Exploring scale-up, spread, and sustainability: an instrumental case study tracing an innovation to enhance dysphagia care. Implement Sci 8(1):128

2. Fleiszer AR et al (2015) The sustainability of healthcare innovations: a concept analysis. J Adv Nurs 71(7):1484-1498

3. Moore JE et al (2017) Developing a comprehensive definition of sustainability. Implement Sci 12(1):110 
4. Proctor E et al (2015) Sustainability of evidence-based healthcare: research agenda, methodological advances, and infrastructure support. Implement Sci 10(1):88

5. Schell SF et al (2013) Public health program capacity for sustainability: a new framework. Implement Sci 8(1):15

6. Shelton RC, Cooper BR, Stirman SW (2018) The sustainability of evidence-based interventions and practices in public health and health care. Annu Rev Public Health 39:55-76

7. Scheirer MA, Dearing JW (2011) An agenda for research on the sustainability of public health programs. Am J Public Health 101(11):2059-2067

8. Greenhalgh T, Papoutsi C (2019) Spreading and scaling up innovation and improvement. BMJ 365:12068

9. Barker PM, Reid A, Schall MW (2016) A framework for scaling up health interventions: lessons from large-scale improvement initiatives in Africa. Implement Sci 11:12. https://doi.org/10.1186/s13012-016-0374-x

10. Shaw J, Tepper J, Martin D (2018) From pilot project to system solution: innovation, spread and scale for health system leaders. BMJ Leader2: 87-90

11. Sholom Glouberman BZ (2013) Complicated and complex systems: what would successful reform of medicare look like? In: C.P.C. Office (ed) Discussion paper 8. Government of Canada

12. Keller HH et al (2019) Multi-site implementation of nutrition screening and diagnosis in medical care units: success of the More-2-Eat project. Clin Nutr 38(2):897-905

13. Laur C et al (2018) The Sustain and Spread Framework: strategies for sustaining and spreading nutrition care improvements in acute care based on thematic analysis from the More-2-Eat study. BMC Health Serv Res 18(1):930

14. Keller $\mathrm{H}$ et al (2020) More-2-Eat implementation demonstrates that screening, assessment and treatment of malnourished patients can be spread and sustained in acute care; a multi-site, pretest post-test time series study. Clin Nutr 40(4):2100-2108

15. Keller HH et al (2015) The Integrated Nutrition Pathway for Acute Care (INPAC): building consensus with a modified Delphi. Nutr J 14:63

16. Keller $\mathrm{H}$ et al (2018) Update on the Integrated Nutrition Pathway for Acute Care (INPAC): post implementation tailoring and toolkit to support practice improvements. Nutr J 17(1):2

17. Laur C et al (2019) Impact of facilitated behavior change strategies on food intake monitoring and body weight measurements in acute care: case examples from the More-2-Eat Study. Nutr Clin Pract 34(3):459-474

18. Laur $\mathrm{C}$ et al (2017) Changing nutrition care practices in hospital: a thematic analysis of hospital staff perspectives. BMC Health Serv Res 17(1):498

19. Ramage-Morin PL, Gilmour H, Rotermann M (2017) Nutritional risk, hospitalization and mortality among community-dwelling Canadians aged 65 or older. Health Rep 28(9):17-27

20. Correia M, Perman MI, Waitzberg DL (2017) Hospital malnutrition in Latin America: a systematic review. Clin Nutr 36(4):958-967

21. Schindler K et al (2017) nutritionDay: 10 years of growth. Clin Nutr 36(5):1207-1214

22. Leij-Halfwerk S et al (2019) Prevalence of protein-energy malnutrition risk in European older adults in community, residential and hospital settings, according to 22 malnutrition screening tools validated for use in adults $\geq 65$ years: a systematic review and meta-analysis. Maturitas 126:80-89

23. Allard JP et al (2016) Malnutrition at hospital admission-contributors and effect on length of stay: a prospective cohort study from the Canadian Malnutrition Task Force. JPEN J Parenter Enteral Nutr 40(4):487-497

24. Curtis LJ et al (2017) Costs of hospital malnutrition. Clin Nutr 36(5):1391-1396

25. Weiner BJ et al (2011) The meaning and measurement of implementation climate. Implement Sci 6(1):78

26. Keller $\mathrm{H}$ et al (2021) More-2-Eat implementation demonstrates that screening, assessment and treatment of malnourished patients can be spread and sustained in acute care; a multi-site, pretest post-test time series study. Clin Nutr 40(4):2100-2108 
27. Bonawitz $\mathrm{K}$ et al (2020) Champions in context: which attributes matter for change efforts in healthcare? Implement Sci 15(1):62

28. Bell JJ et al (2018) Rationale and developmental methodology for the SIMPLE approach: a systematised, interdisciplinary malnutrition pathway for implementation and evaluation in hospitals. Nutr Diet 75(2):226-234

29. Bell, JJ, Young, AM, Hill, JM, et al (2021) Systematised, Interdisciplinary Malnutrition Program for impLementation and Evaluation delivers improved hospital nutrition care processes and patient reported experiences - An implementation study. Nutr Diet 1-10. https:// doi.org/10.1111/1747-0080.12663

30. Nilsen P (2015) Making sense of implementation theories, models and frameworks. Implement Sci 10(1):53

31. Moullin JC et al (2015) A systematic review of implementation frameworks of innovations in healthcare and resulting generic implementation framework. Health Res Policy Syst 13:16

32. Luke DA et al (2014) The program sustainability assessment tool: a new instrument for public health programs. Prev Chronic Dis 11:E12

33. Doyle C et al (2013) Making change last: applying the NHS institute for innovation and improvement sustainability model to healthcare improvement. Implement Sci 8:127

34. Graham ID et al (2006) Lost in knowledge translation: time for a map? J Contin Educ Heal Prof 26(1):13-24

35. Hailemariam M et al (2019) Evidence-based intervention sustainability strategies: a systematic review. Implement Sci 14(1):57

36. Milat AJ, Bauman A, Redman S (2015) Narrative review of models and success factors for scaling up public health interventions. Implement Sci 10(1):113

37. Geerligs L et al (2018) Hospital-based interventions: a systematic review of staff-reported barriers and facilitators to implementation processes. Implement Sci 13(1):36

38. Birken SA et al (2020) Advancing understanding and identifying strategies for sustaining evidence-based practices: a review of reviews. Implement Sci 15(1):88

39. Woodward EN et al (2019) The health equity implementation framework: proposal and preliminary study of hepatitis C virus treatment. Implement Sci 14(1):26

40. Chinman M, et al (2017) Harnessing implementation science to increase the impact of health equity research. Med Care 55 Suppl 9 Suppl 2(Suppl 9 2):S16-S23.

41. Baumann AA, Cabassa LJ (2020) Reframing implementation science to address inequities in healthcare delivery. BMC Health Serv Res 20(1):190

\section{Recommended Reading}

Greenhalgh T, Papoutsi C (2019) Spreading and scaling up innovation and improvement. BMJ 10:365

Intervention Scalability Assessment Tool (ISAT). https://preventioncentre.org.au/wp-content/ uploads/2019/11/The-ISAT-Oct-2019_FINAL.pdf

Keller H, Koechl JM, Laur C, Chen H, Curtis L, Dubin JA, Gramlich L, Ray S, Valaitis R, Yang Y, Bell J (2021) More-2-Eat implementation demonstrates that screening, assessment and treatment of malnourished patients can be spread and sustained in acute care; a multi-site, pretest post-test time series study. Clin Nutr 40(4):2100-2108

Laur C, Valaitis R, Bell J, Keller H (2017) Changing nutrition care practices in hospital: a thematic analysis of hospital staff perspectives. BMC Health Serv Res 17(1):498

Laur C, Bell J, Valaitis R, Ray S, Keller H (2018) The Sustain and Spread Framework: strategies for sustaining and spreading nutrition care improvements in acute care based on thematic analysis from the More-2-Eat study. BMC Health Serv Res 18(1):930 
Shaw J, Tepper J, Martin D (2018) From pilot project to system solution: innovation, spread and scale for health system leaders. BMJ Leader 2(3):87-90

The INPAC Implementation Toolkit. http://m2e.nutritioncareincanada.ca/

The Program Sustainability Assessment Tool. https://www.sustaintool.org/

Open Access This chapter is licensed under the terms of the Creative Commons Attribution 4.0 International License (http://creativecommons.org/licenses/by/4.0/), which permits use, sharing, adaptation, distribution and reproduction in any medium or format, as long as you give appropriate credit to the original author(s) and the source, provide a link to the Creative Commons license and indicate if changes were made.

The images or other third party material in this chapter are included in the chapter's Creative Commons license, unless indicated otherwise in a credit line to the material. If material is not included in the chapter's Creative Commons license and your intended use is not permitted by statutory regulation or exceeds the permitted use, you will need to obtain permission directly from the copyright holder.

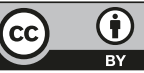

